\title{
O centenário de Nietzsche e o nazismo
}

\author{
Evaristo de Morais Filho**
}

\begin{abstract}
Resumo: Artigo publicado no jornal carioca Diário de Notícias, em 1945. Em oposição às abordagens que teimam em associar Nietzsche com o nazismo, Evaristo M. Filho procura tirar algumas conclusões políticas de sua obra contrárias ao espírito nazista. Acusa os suspeitos e apressados divulgadores de sua filosofia, como Will Durant, de injustamente situá-lo como mandante espiritual dos crimes praticados pelos nazifascistas.

Palavras-chaves: Nietzsche - centenário - nazismo - fascismo
\end{abstract}

Já se encontrava casado o pastor da igreja luterana Karlludwig Nietzsche havia mais de quadro anos, e esperava ansiosamente pelo seu primeiro filho, quando a 15 de outubro de 1844, dia do aniversário do rei Frederico Guilherme IV, da Prússia, veio ao mundo Frederico Nietzsche, nascido na pobre aldeia de Röcken.

$\mathrm{E}$ agora, passados cem anos, quase ninguém se lembra mais de comemorar com alegria esta grande data para a humanidade, apontando no filho do pastor luterano um dos cúmplices desse assalto armado à civilização que assistimos no momento, imposto por Hitler e sua camarilha fascista. E o que deveria ser uma festa de entusiasmo e aplauso transforma-se em motivo de tristeza e maldição. É que a imagem de Nietzsche não pode mais ser lembrada sem a sombra envolvente da mascara de Adolf. Para confundi-las completamente basta reduzir-lhe os grossos bigodes e jogar-lhe um pouco de pastilha pela testa abaixo.

\footnotetext{
* Publicado no Diário de Notícias. Rio de Janeiro, 04 de Fevereiro de 1945, p. 05.

** Evaristo de Morais Filho (1914). Escritor e Membro da Academia Brasileira de Letras.
} 
Morais Filho, E.

Deste modo, com a maior simplicidade desta vida, por culpa de divulgadores apressados e suspeitos, desses que metem os autores em formas intelectuais como quem encomenda empadas na confeitaria da esquina, viu-se o infeliz solitário de Sils Maria reduzido a mero mandante espiritual dos crimes praticados pelos sanguinários bandidos nipo-nazi-fascistas. Afinal de contas, isso é menosprezar demais a dignidade de quem sempre viveu pobre e infeliz, afastado dos prêmios do mundo oficial, preocupado em todos os instantes com o destino da criatura humana neste planeta. Se já houve algum pensador sério e honesto, nobre e puro, na história da filosofia, esse alguém se chamou Frederico Nietzsche.

Não nego que seja fácil encontrar em sua obra farto material que sirva de fundamento doutrinário do nazismo, mas, por outro lado, também seria bem fácil colher ali inúmeros argumentos contra esse mesmo nazismo. A filosofia de Nietzsche, pela forma com que foi exposta - de aforismos e contradições constantes - serve de ponto de referência para mais de uma direção política. Tanto pode ficar no centro, como caminhar para a direita ou orientar-se para a esquerda. $\mathrm{O}$ que menos preocupou Nietzsche foi ver aplicadas na prática as suas frases soltas, lançadas no papel ao correr da pena, entre uma e outra dose de cloral, como marcos felizes dos seus intervalos sem dor. Vivesse ainda Nietzsche, e estou certo, veria ele no nazismo o exemplo mais cruel da sua moral de rebanho e de escravos, de filisteus da cultura, de covardes que se assenhoraram ardilosamente do poder para o desafogo de vinganças e ressentimentos recalcados.

Para aqueles divulgadores apressados e suspeitos, de que falei há pouco, tipo Will Durant, a filosofia de Nietzsche resume-se em duas expressões: o super-homem e a vontade do poder. Nada mais errôneo, no entanto. Como muito bem o esclareceram os seus intérpretes mais autorizados, o pensamento nietzschiano atravessou três fases inteiramente diversas entre si. Na sua mocidade, quando se dedicava ao estudo da filologia clássica, ao tempo em que lecionou esta matéria na Universidade de Basileia, era seu ideal filosófico o 
artista trágico. São esta época "A origem da tragédia" (1872) e as "Considerações inatuais" (1874-76).

Já no período seguinte, com "Humano, demasiado humano" (1878-80), "Aurora" (1881), e "Gaya Scienza" (1882), como que caindo em si do perigoso devaneio romântico em que andou, volta ao mundo do sonho e da fantasia, procura aprofundar-se no conhecimento da própria realidade viva e concreta que o cerca por todos os lados. Aí então desloca o seu ideal filosófico da arte para a ciência, e passa a vê-lo realizado no sábio e no livre pensador. Somente na terceira fase, quando já se avizinhava de Nietzsche a loucura definitiva que o havia de matar, é que ele aceita o super-homem como ponto central do seu sistema, principalmente em "Assim falava Zaratustra" (1883-85), e "A vontade de poder" (1888).

A verdade é que o superhumanismo de Nietzsche, com a sua invencível vontade de poder, nada mais era do que a compensação imaginativa de um homem pacato e solitário, que de conquista e domínio não ia além do seu jardim. E ainda assim, só quando fazia sol... A sua criação foi um exemplo da sua própria filosofia de que (La Gaya Scienza - prefácio da $2^{\circ}$ edição) "em uns são deficiências que fazem os raciocínios filosóficos; em outros, as riquezas e as forças". E dizia linhas acima: "Mas deixemos por lá o sr. Nietzsche. Que nos importa que o sr. Nietzsche tenha recuperado a saúde?... Um psicólogo conhece poucas questões tão atraentes como a da relação da saúde com a filosofia".

Nietzsche, que servira como enfermeiro a guerra de 1870, contraiu uma doença crônica de fundo nervoso que jamais o haveria de abandonar até à morte, a despeito de toda a ciência médica do seu tempo. Ainda hoje muito se discute qual tenha sido essa moléstia. O fato é que o autor de "Ecce Homo" sofria de dores terríveis em todo o corpo, a particularmente na cabeça, a ponto de não poder escrever uma linha ou ligar duas ideias sequer. Como é natural, fez ele da filosofia a terapêutica para os seus males, como Pascal que se curava das dores de dente com matemática.

A concepção do mundo e da vida nada mais é do que o canto 
Morais Filho, E.

dessa vitória sobre o incessante tormento de dores físicas e espirituais, que o assaltavam constantemente e procuravam aniquilá-lo a cada crise mais violente. Daí a sua filosofia da resistência, de vontade de poder, de afirmação da vida. Era preciso desafiar e vencer as habilidades do corpo, e aceitar sempre a vida, ainda que dolorosa e má. Não só aceitá-la, como também desejá-la de volta uma infinidade de vezes, com as mesmas angústias, com os mesmos sofrimentos. Nascia assim a teoria do eterno retorno de todas as coisas desta existência, que se repetiriam outras vezes em outros lugares e em outros tempos com todas as particularidades presentes. Significa esta teoria o triunfo mais alto sobre a tortura cotidiana de Nietzsche: uma vez é pouco, que velha um milhão de vezes, e ele resistirá! Na "Vontade de Poder", escreveu que "o homem superior se distingue do homem inferior por sua intrepidez e seu desafio à desgraça". E em "Assim falava Zaratustra": "Meus amigos, todos que estais aqui presente - disse o mais feio dos homens - que vos parece? Graças a Zaratustra estou pela primeira vez satisfeito de ter vivido a vida inteira. $\mathrm{E}$ ainda não me basta tal declaração. Vale a pena viver na terra: um dia, uma festa em companhia de Zaratustra me ensinaram a amar a terra. Era isto a vida? - direi à morte. - Pois bem: repita-se".

Não queria Nietzsche fazer da humanidade uma minoria de super-homens a tiranizar e a gozar a maioria de outros pobres homens comuns. Não, ao contrário. A certa altura, pergunta: "Que é o macaco para o homem?", e responde: "Uma irrisão ou uma dolorosa vergonha. Pois é o mesmo que deve ser o homem para o super-homem: uma irrisão ou uma dolorosa vergonha".

Em outro trecho exclama: "Amo os homens". Mais adiante: "Um raio de luz me atravessa a alma: preciso de companheiros, mas vivos e não de companheiros mortos e cadáveres, que levo para onde quero. Preciso de companheiros, mas vivos, que me sigam - porque desejem seguir-me a si mesmos - para onde quer eu vá. Um raio de luz me atravessa a alma: não é à multidão que Zaratustra deve falar, mas a companheiros! Zaratustra não deve ser

204 | Cad. Nietzsche, São Paulo, v.36 n.1, p. 201-211, 2015. 
pastor e cão de um rebanho! Para apartar muitos do rebanho, foi para isso que vim. O povo e o rebanho irritam-se comigo. Zaratustra quer ser acoimado de ladrão pelos pastores. Eu digo pastores, mas eles a si mesmos se chamam os fieis da verdadeira crença! O criador procura companheiros, não procura cadáveres, rebanhos, nem crentes; procura colaboradores que inscrevam valores novos ou taboas novas".

Pois bem, não está contida neste pequeno trecho toda a crítica do nazismo e do princípio do chefe? O que importa são os companheiros vivos e livres, independentes e em permanente atitude crítica, colaboradores, enfim, e não crentes, fanáticos, fantoches movidos a barbante, como são esses infelizes componentes de milícias fascistas, cujo primeiro juramento é deixar de pensar e de indagar a respeito do seu destino, concordando sempre com o chefe infalível e onipotente.

Enquanto que os nazistas são uns gozadores, reduzindo a criatura humana a um simples animal instintivo e sedento de prazeres os mais baixos possíveis, entregando-se ao deboche, ao sadismo, à luxuria sensualista a mais desbravada, a concepção de Nietzsche frente aos instintos é profundamente estoica e ascética. Se o tipo nietzschiano quer e pode, colocando-se acima do bem e do mal, é porque procura superar-se a si mesmo pela dor. Na realidade, um autêntico cristão, embora Nietzsche pretendesse derrubar e acabar com o mínimo vestígio de cristianismo na terra. Usando da frase que proferiu uma das personagens de D’Annunzio, comparsa iniciador do fascismo italiano, bem poderiam dizer os nazistas que "quem muito sofreu é menos sábio do que quem muito gozou”. Nietzsche pregava justamente o contrário, ao declarar que "o homem que se entrega ao gozo terrível é o último dos seres".

Em verdade, a aristocracia do genial criador do super-homem era somente de vontade, como alguma coisa de dinâmico, de eterno vir-a-ser, de luta constante contra a fraqueza e a debilidade do homem. Não tinha nada de elemento social, e muito menos de classes privilegiadas. Tanto é assim que o verdadeiro ser superior pode 
Morais Filho, E.

encontrar-se tanto entre as classes ricas como entre as classes podres da sociedade atual. $\mathrm{O}$ que Nietzsche chamava de filisteu era justamente o homem fátuo, com uma espécie de cultura cor-de-rosa e elevada posição social, em uma palavra, o parvenu e o burguês em geral. A sua moral de escravos e de senhores nada tem a ver com a presente estratificação da sociedade. E é justamente por se levantar contra esse estado de coisas que Nietzsche anuncia uma nova transmutação de todos os valores, que pode ser resumida nestas poucas linhas do $§ 86$, do $1^{\circ}$ volume de "A vontade de poder": "Ensino a dizer não em face de tudo o que torna fraco ou de tudo o que esgota. Ensino a dizer sim em face de tudo que fortifica, de tudo que acumula forças, do que justifica o sentimento de vigor".

Como se vê, não se refere a nenhum elemento social, a nenhum privilégio de sangue ou de dinheiro. Para Nietzsche, o importante é a aristocracia da vontade - "Aristocratie des Willens". Os senhores e os escravos encontram-se indiferentemente entre os proletários e os burgueses atuais, caracterizam-se mais por uma diferença estritamente psicológica do que social. Trata-se de "almas senhoriais" e de "almas servis". Toda a moral vigente é de escravos, "porque conduz necessariamente à decadência, à conservação e à multiplicação da miséria, transformando a terra num grande hospital".

Aliás, é esta falta de elemento social na obra de Nietzsche o que a torna evidentemente mais frágil e criticável. Pretendeu ele construir uma filosofia fora do tempo e do espaço, à maneira de uma pomba que voasse no vácuo. Pensou com isso escapar às correntes e às lutas de seu tempo, procurando ignorar as lutas sociais que se desenrolavam diante dos seus olhos. A sua atitude como pensador é a de um romântico, entregue aos seus problemas íntimos, de sentimento e de cultura, indiferente à sorte do mundo. Contudo, podem-se tirar algumas conclusões políticas da sua obra inteiramente contrárias ao espírito nazista.

Em mais de uma passagem ataca Nietzsche acerbamente o Estado, a organização estatal, como uma verdadeira instituição de rapinagem oficializada que se impõe pela força. Vale este trecho 
(af. 326, da "Vontade de Poder"): "O Estado ou a imoralidade organizada - no interior sob a forma de polícia, de direito penal, de casta, de família; no exterior, como vontade de poder, de guerra, de conquista, de vingança".

A negação do Estado por Nietzsche chegou a tal ponto que certa feita escreveu que "cultura e Estado são inconciliáveis". E no aforismo 481 do "Humano, demasiado humano", lê-se essa crítica ao armamentismo, ao chauvinismo patriótico, à guerra, como não faria melhor nenhum de nós, que estamos assistindo diretamente as consequências desses fatos: "Do mesmo modo que um povo sofre os grandes prejuízos que ocasiona a guerra e a preparação desta pelos gastos de guerra, pelas perturbações do comércio e das comunicações, nem tão pouco pela manutenção dos exércitos permanentes - por graves que possam ser estes prejuízos, hoje oito Estados da Europa gastam nisso anualmente a soma de cinco mil milhões mas também porque de ano em ano os homens mais sãos, os mais fortes, os mais laboriosos, se veem arrancados de suas ocupações e de suas vocações próprias para ser sodados, do mesmo modo a um povo que se constitui no dever de fazer grande política e assegurar-se uma situação preponderante entre as potências não sofre os mais graves prejuízos onde os encontra comumente. É verdade que a partir deste momento sacrifica continuamente uma multidão de talentos de primeira ordem "no altar da pátria" ou por ambição nacional, enquanto que esses talentos, que agora devora a política, encontram abertos outros campos de ação".

E termina, de maneira incisiva contra o nacionalismo: "Há verdadeiro proveito se a estas flores grosseiras e mal pintadas do nacionalismo temos de sacrificar todas as plantas e ervas mais nobres, mais ternas, mais intelectuais, que tanto enriqueciam seu solo?".

De outra feita, escreveu ainda Nietzsche: "A xenofobia doentia que a loucura nacionalista semeou ainda entre os povos da Europa, não passa de uma política de intervalo". E atacando diretamente o Reich bismarquiano do seu tempo, dizia que era bem triste assistir o Reich armar-se até os dentes, transformando-se em um "ouriço 
Morais Filho, E.

heroico", esquecido de que foi uma nação que produziu realmente grandes pensadores. No "Crepúsculo dos Ídolos", exclama: "O que as escolas alemãs atingem, com efeito, é um adestramento brutal para tornar utilizável, explorável para o serviço do Estado, uma legião de jovens, Educação superior e religião, eis aí uma contradição primordial".

No "Humano, demasiado humano", escreve (af. 276): "A democratização da Europa é irresistível", e conclui pouco adiante (af. 292): "O resultado prático desta democratização, que vai sempre em aumento, será, em primeiro lugar, a criação de uns Estados unidos europeus, nos quais cada país, delimitado segundo suas condições geográficas, ocupará a situação de um cantão e possuirá os seus direitos particulares. Então, serão tidas em muito pouca conta as recordações históricas dos povos, tais como existiram até o presente, porque o sentido da piedade que rodeia estas recordações será pouco a pouco desenraizado sob o império do princípio democrático, ávido de inovações e de experiências".

E sobre o judeu, que pensaria Nietzsche? Nada mais, nada menos do que isso: contrário a qualquer preconceito de raça e arianismos idiotas (af. 475, "Humano"): "Quando se trata não somente de conservar ou de estabelecer nações, mas também reproduzir e elevar uma raça mista de europeus, a mais forte possível, o judeu é um ingrediente mais útil e desejável que nenhum outro elemento nacional. Toda nação, todo homem tem rasgos desagradáveis e ainda perigosos; é bárbaro querer que o judeu seja uma exceção".

Neste mesmo aforismo, mostrando que o problema judaico só pode ter existência real quando se levantam as questões das nacionalidades estanques, aproveita a ocasião para apontar a falsidade desses supostos nacionalismo: "O comércio e a indústria, a comunidade de toda a alta cultura, a rápida mudança de lugar e de país, a vida nômade de todos os que atualmente não possuem terra: todas estas condições acarretam necessariamente um debilitamento, e por último, uma destruição das nações, pelo menos, das nações europeias. A este fim se opõe atualmente, consciente ou 
inconscientemente, o exclusivismo das nações pela produção das inimizades "nacionais", mas a marcha desta mescla não é menos lenta, apesar de todas as correntes contrárias do momento. Este nacionalismo artificial é, além disso, tão perigoso como o foi o catolicismo artificial, pois é por essência um estado de coação, um estado de sítio forçado, imposto por um pequeno número ao grande número, e necessita do ardil, da mentira e da violência para manter seu credito".

$\mathrm{Na}$ "Vontade de Poder", leem-se esses dois trechos inequívocos sobre o destino dos trabalhadores do mundo moderno: "Os operários deveriam aprender a reagir como soldados. Honorários, vencimentos, mas nada de salários! Nenhuma relação entre pagamento e trabalho! Colocar cada indivíduo, de acordo com sua natureza, no lugar onde pode produzir o mais possível dentro de sua especialização". E depois: "Os operários viverão um dia como vivem atualmente burgueses; mas acima deles, distinguindo-se pela ausência de necessidades, viverá a casta superior, mais podre e mais simples, dona, entretanto, do poder".

E pregava para os operários o mesmo ascetismo que simboliza o verdadeiro cientista, exclamando, sem rebuços: "Nós somos todos operários".

Tudo isso que ficou aí citado, entre aspas, é a negação formal e completa da afirmação gratuita e ligeira de que Nietzsche é a inspiração imediata e direta do nazismo. Mentira ou ignorância de quem afirma. $\mathrm{O}$ que Hitler conseguiu fazer da Alemanha dominada, sob o terror da sua "Gestapo" assassina foi uma sub-humanidade de analfabetos, fanáticos e carcereiros, destituídos de vontade própria e seguidores cegos das suas ordens. A doutrina da vontade de poder de Nietzsche tanto pode ser aplicada ao nazismo como ao seu oposto político e ideológico, isto é, à doutrina da luta de classes. Também aqui, nada mais se trata do que uma luta pelo poder, em que o fraco tem de organizar-se e tornar-se forte, para conquistá-lo. E isso nos faz lembrar do caso de Hegel, que se por um lado deu as esquerdas marxistas; por outro, inspirou a constituição do Estado 
Morais Filho, E.

alemão forte e centralizador, por sua teoria endeusadora do Estado, como único detentor legítimo da cultura social.

Os grandes pensadores são vítimas, às vezes, da falta de visão social e política. Ambiciosos da posteridade, do mundo idealista da pura ficção doutrinária e retórica, esquecem-se de que são homens que vivem na terra, entre o tumultuo de todos os dias, no meio de outros homens que sofrem, anseiam e lutam pela modificação do estado que os cercam. Com a cabeça metida nas nuvens, verdadeiros pagãos da cultura, não se perturbam esses fazedores da filosofia pela necessidade de que tem de tomar partido, e de que os seus pés caminham também pisando o chão duro da realidade. E por isso tornam-se vítimas fáceis de futuros aproveitadores das suas doutrinas, para justificar a prática inconfessável dos seus crimes contra a civilização.

Nietzsche foi um cidadão do mundo, de todos os tempos e de todos os países. Foi um homem na mais pura acepção da palavra, criou uma filosofia universal, sem estandartes, nem fronteiras. $\mathrm{O}$ seu homem superior não precisava de passaporte, porque a sua pátria era o universo inteiro. Estava onde estivessem todos os que "vivessem como homens superiores e realizassem os fins superiores da civilização". O suposto super-homem do nazismo nada tem a ver com a filosofia de Nietzsche, pelas suas características de educação de rebanho, de nacionalismo artificial, racista, alheado a qualquer problema da cultura e do espírito.

Nesta limitação de horizontes, camuflado, falsificado e explorado, seria Nietzsche o primeiro a sentir revoltar e repudiar este parentesco indesejável que, a todo custo, lhe querem atribuir com o nazismo. É sempre comum aos regimes oportunistas e sem doutrina própria apontar nos grandes escritores razões de ser do seu advento. Basta lembrar o cinismo dos teóricos integralistas, quando começaram a pregar que Euclides da Cunha e Castro Alves tinham sido os precursores daquela farra verde e que, se fossem vivos, iriam por certo para a fila da Travessa do Ouvidor, requerer a sua carteirinha de sócio...

210 I Cad. Nietzsche, São Paulo, v.36 n.1, p. 201-211, 2015. 


\begin{abstract}
Article published in the newspaper Diário de Notícias, in 1945, in Rio de Janeiro. In contrast to approaches that insist on Nietzsche associate with Nazism, the author tries to draw some policy conclusions of his work contrary to Nazi spirit. Accuses the suspects and rushed disseminators of his philosophy, as Will Durant, unfairly place it as spiritual mastermind of the crimes committed by the Nazi-fascist.
\end{abstract}

Keywords: Nietzsche - centenary - nazism - fascism 
